\title{
Online Supercapacitor Health Monitoring Using a Balancing Circuit
}

\author{
Seïma SHILI ${ }^{\mathrm{a}} *$, Alaa Hijazi ${ }^{\mathrm{b}}$, Ali Sari ${ }^{\mathrm{a}}$, Pascal Bevilacqua ${ }^{\mathrm{b}}$, Pascal Venet ${ }^{\mathrm{a}}$ \\ ${ }^{a}$ Laboratoire Ampère, UMR CNRS 5005 Université de Lyon, Université Claude Bernard Lyon 1, 43 bd du 11 novembre 1918, Bât. Omega Villeurbanne, F-69622 \\ Cedex, France. \\ ${ }^{b}$ Laboratoire Ampère, UMR CNRS 5005 Université de Lyon, INSA de Lyon, 21 av. Jean Capelle, Bât. Léonard de Vinci Villeurbanne, F-69621 Cedex, France.
}

\section{ARTICLE INFO}

\section{ABSTRACT}

\section{Article history:}

Received

Received in revised form

Accepted

Available online

\section{Keywords}

Balancing circuit

Battery Management System (BMS)

Electrochemical Double-Layer Capacitor (EDLC)

Estimated Life Duration (ELD)

State Of Health (SOH)

Supercapacitor

\section{Introduction}

Due to their high energy and power density, supercapacitors [1], also known as ultracapacitors [2], or electrochemical double-layer capacitors (EDLC) [3][4][5], are nowadays becoming a popular new generation of storage systems for high-power applications [6][7].

In spite of their good electrical performances, supercapacitors are limited by their terminal voltages not exceeding $3 \mathrm{~V}$. So, they are placed in a chain structure in order to obtain a suitable voltage. Thus, the supercapacitor storage system is composed of an association of elementary cells, called storage string, pack or stack [8].

For security and reliability reasons, a supercapacitor storage system, like most of storage systems, should be monitored and controlled by a management system. This system may be called SCM (Supercapacitor Manager), equivalent to the BMS (Battery Management System). SCM is composed of software and hardware units. It includes monitoring, state estimating and balancing functions for each pack element (cell) [9][10].

Temperature and voltage monitoring prevent the elements from exceeding their maximum operating range and ensure both user and system's safety.

Users need information about the state of their system. Therefore, the state of charge (SOC) is required to verify the autonomy of the system. The state of health $(\mathrm{SOH})$ is needed to prevent the replacement of the system. Those indications are provided by the SCM software unit which treats the measured data, such as system temperatures, currents and voltages, to estimate the state of cells.

In addition to monitoring and states' estimation, balancing functions adjust the voltage or the state of charge between the elements of a unique pack. It is compulsory to include this function on the SCM. Indeed, even if cells in the string are subject to the same current, a dispersion of voltage or SOC is obviously present and must be reduced. The principal reason of this dispersion is the differences between cells intrinsic characteristic due to manufacturing tolerance. In addition, during an operation, the differences between cells become more and more pronounced due to the temperature dispersion inside the stack and the aging of each element.

The balancing circuit reduces voltage imbalances between chain elements, thus prolonging the system's lifetime [11]. Depending on the circuit architecture, the balancing function is classified in a dissipative or non-dissipative category [12][13]. The dissipative one dissipates the excess of energy through the balancing resistor [14][15]. The non-dissipative one distributes the excess of energy between elements using capacitors, inductors or transformers [16][17]. The non-dissipative balancing seems more attractive, but the dissipative one remains widely used in the marketplace due to its simplicity and low cost. For supercapacitor energy storage systems, dissipative equalization method is the only technique existing in the market today

The aim of this paper is to incorporate a new function in the balancing circuits to deal with $\mathrm{SOH}$ identification problem. Nowadays the online state estimation is one of the main focuses of 
research in the area of energy storage system applications. The research tries to develop mathematical algorithms (observers) based on automatic theories to estimate the aging of a storage element. However, in most cases these algorithms are greedy in terms of the computation time and their performances depend highly on the chosen model accuracy [18][19].

The presented work proposes a new method for estimating the $\mathrm{SOH}$ of an energy storage element. It uses a dissipative balancing circuit, the switched shunt resistor circuit which is composed of a serial association of a resistor and a switching MOSFET. This circuit is connected to the terminals of each storage system cell. The new strategy of health monitoring focuses on quantifying online the supercapacitor specific impedance which represents the aging of the element. Thus, in the first part of this paper, the supercapacitor impedance behavior and the aging effect will be introduced. In the second part, the principle of a new approach for the $\mathrm{SOH}$ and the estimated life duration (ELD) determination will be presented. In the third part, the test bench realization and the new approach implementation will be presented. Then, a comparison between famous laboratory results and the new method will be carried out in order to evaluate the accuracy of this new approach.

\section{Supercapacitor aging effect}

The supercapacitors offer higher lifespan than electrochemical accumulators. Indeed, they can support hundreds of thousands deep discharge and charge cycles thanks to the theoretical lack of chemical reactions at the electrodes. However, there are some impurities inside the supercapacitor called functional groups due to manufacturing imperfect process [20]. During aging, functional groups produce solid and gaseous reactions damaging the supercapacitor [21]. The aging process of supercapacitors affects mainly the capacitance and the equivalent series resistance (ESR) [22][23]. The capacitance, C, represents the supercapacitor ability to store an electrical charge. The equivalent series resistance is the resistance corresponding to all the resistive components within the supercapacitor. Experiments demonstrate a slow evolution of the capacitance and the ESR simultaneously over aging until failure depending on the solicitation [24][25]. The supercapacitor is defined as defective by the manufacturer when its equivalent series resistance generally increases to a value equal to twice its initial value or when its capacitance falls below $80 \%$ of its initial value. These ESR and $\mathrm{C}$ failure values could be different according to the application requirement [26]. Hence, the state of health monitoring is realized by following the evolution of at least one of those parameters. The comparison between instantaneous and initial values reflects the actual age of the element.

The method presented focuses on the estimation of the actual ESR in order to evaluate the supercapacitor's state of health. The instantaneous ESR estimated is then compared to its initial value obtained under same environmental conditions to estimate the aging of the cell. Thus, the method could also predict the life duration under specified conditions and forecast a replacement.

In the following section, offline characterizations and the new suggested approach are introduced in order to analyze supercapacitor's ESR behavior. Thereafter, results obtained by the classical offline characterization will be used as references for results validation.

\section{Electrochemical impedance spectroscopy and supercapacitor frequency behavior}

There are two main methods used to analyse the performance of supercapacitors: the temporal characterization method based on the electrical behaviour when charging and discharging the cell and the frequency method based on the electrochemical impedance spectroscopy. Both methods lead to the acquisition of parameters that are considered sufficient to describe the properties of the supercapacitor in time and spectral domain [27][28].

The temporal method is not presented in this paper. The frequency method is used since the impedance spectroscopy is more precise and gives further information.

Electrochemical Impedance Spectroscopy (EIS) is an accurate state evaluation method for supercapacitors and other electrical energy storage systems [29][30]. It determines the system's impedance for different frequencies. Its principle consists on injecting a sinusoidal signal of low amplitude in a range of frequencies in order to represent the impedance of the element for each frequency as in (1).

$$
\underset{-}{Z}(f)=\frac{V(f)}{I(f)}=\operatorname{Re}(\underset{-}{Z}(f))+j \operatorname{Im}\left(Z_{-}(f)\right)
$$

Collected data allow different representations of the impedance. Figures. 1 and 2 show the Bode representations for different supercapacitors, characterized at $2.7 \mathrm{~V}$ and $25^{\circ} \mathrm{C}$.

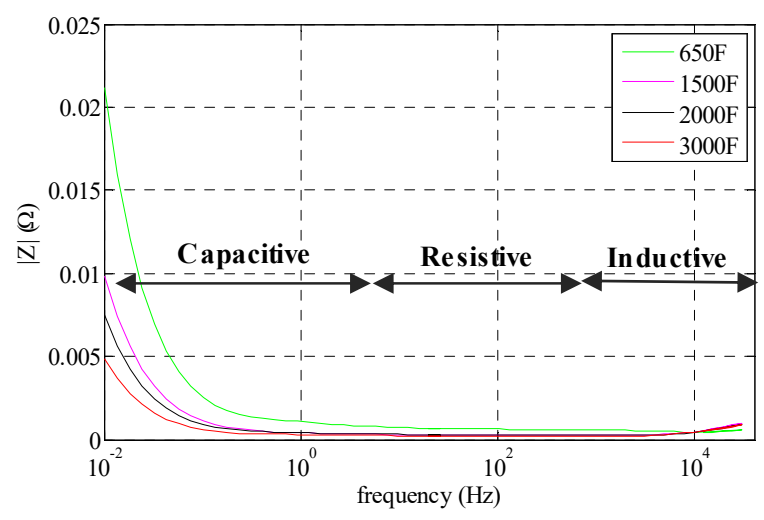

Fig. 1. Bode module diagram of different supercapacitor' impedances at $2.7 \mathrm{~V}$ and $25^{\circ} \mathrm{C}$.

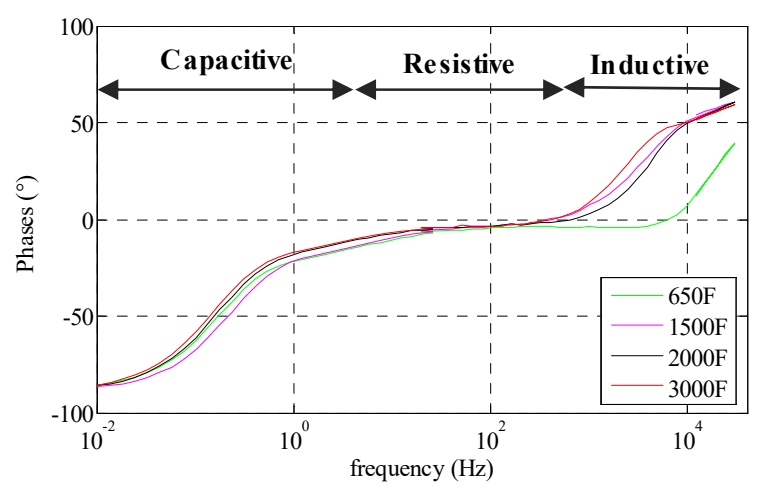

Fig. 2. Bode phase diagram of different supercapacitor' impedances at $2.7 \mathrm{~V}$ and $25^{\circ} \mathrm{C}$.

According to the impedance phase diagram presented in Fig. 2, the curves can be divided into three principal parts (mostly capacitive, inductive and resistive impedance). When the phase's curves cross zero degree, the behavior of the supercapacitor is purely resistive (absence of imaginary part). The frequency corresponding to this real impedance is called resonance frequency. The corresponding module of impedance represents the ESR at the resonance frequency and will be named Ro. The internal parameter monitored by the characterization approach presented in this paper is the parameter Ro. 
First, for a frequency band $\Delta \mathrm{fr}$, ranging from approximately $10 \mathrm{~Hz}$ to $1 \mathrm{kHz}$, the supercapacitor impedance modulus represented in Fig. 1 is quasi constant and close to Ro values (less than 1\% maximum variation). Indeed, inside this bandwidth around the resonance frequency the capacitive and inductive behaviors are negligible.

Supercapacitor aging affects the cell impedance. Fig. 3 and 4 represent different Bode impedance curves corresponding to different aging states of a $2.7 \mathrm{~V} / 3000 \mathrm{~F}$ supercapacitor. Aging is due to $2600 \mathrm{~W}$ charge/discharge cycles at an ambient temperature of $60{ }^{\circ} \mathrm{C}$.

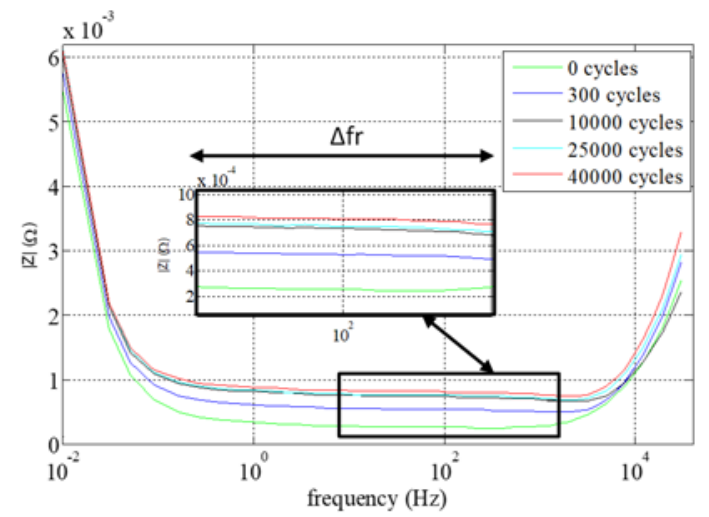

Fig. 3. Bode module diagram of aged $3000 \mathrm{~F}, 2.7 \mathrm{~V}$ supercapacitor impedances at $1 \mathrm{~V}$ and $25^{\circ} \mathrm{C}$

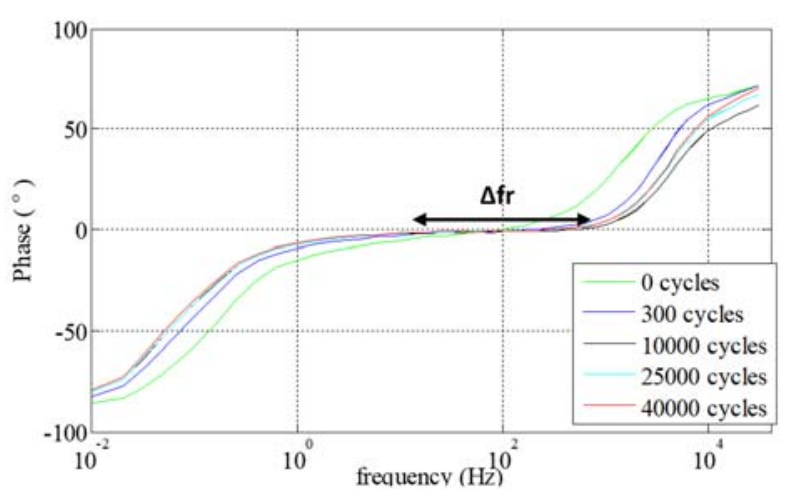

Fig. 4. Bode phase diagram of aged $3000 \mathrm{~F}, 2.7 \mathrm{~V}$ supercapacitor impedances at $1 \mathrm{~V}$ and $25^{\circ} \mathrm{C}$

The impedance modules traced in Fig 3 show clearly the increase of ESR with applied cycles. Indeed, module curves are shifted up. However, the frequency band for quasi-resistive impedance module remains the same. Therefore, the bandwidth $\Delta \mathrm{fr}$ also remains the same independently of the aging of element.

\section{New health monitoring approach}

\subsection{Characterization principles}

The aim of the new identification method is to extract the supercapacitor actual Rot. Rot corresponds to the modulus of the supercapacitor impedance when working at resistive zone It is equal to the effective value of supercapacitor voltage divided by its current in the resonance frequency.

Firstly, the analysis above shows that the modulus of the cell's impedance is constant along the bandwidth $\Delta \mathrm{fr}$ and close to ESR at the resonance frequency Ro (see Fig. 1 and 3). Therefore, it is possible to measure the Rot, not only at one specific frequency value but also at any value in this frequency band. Secondly, $\Delta \mathrm{fr}$ remains the same with different supercapacitor capacitances (see Fig. 1). The freedom of frequency choices presents a real advantage for the suggested method that can be generalized to a large supercapacitor range. Thirdly, the resistive bandwidth $\Delta \mathrm{fr}$ is the same whatever the aging of the element (see Fig. 3). Thus, for a wide supercapacitor's capacity range at any state of health, measuring the impedance of the cell at a frequency between approximately $10 \mathrm{~Hz}$ and $1 \mathrm{kHz}$ allows obtaining a quasi-resistive response equal to the ESR at resonance frequency (Ro).

The analysis presented focuses on high capacity supercapacitors. Indeed, the use of health monitoring is more relevant. However, it could be generalized to smaller capacities (less than $650 \mathrm{~F}$ ) or with rated voltage other than $2.7 \mathrm{~V}$ for supercapacitors with the same technology.

To extract the instantaneous Rot, one can generate voltage and current ripples at a frequency, fo, inside the bandwidth $\Delta \mathrm{fr}$, by controlling the switch of the balancing circuit using a duty cycle.

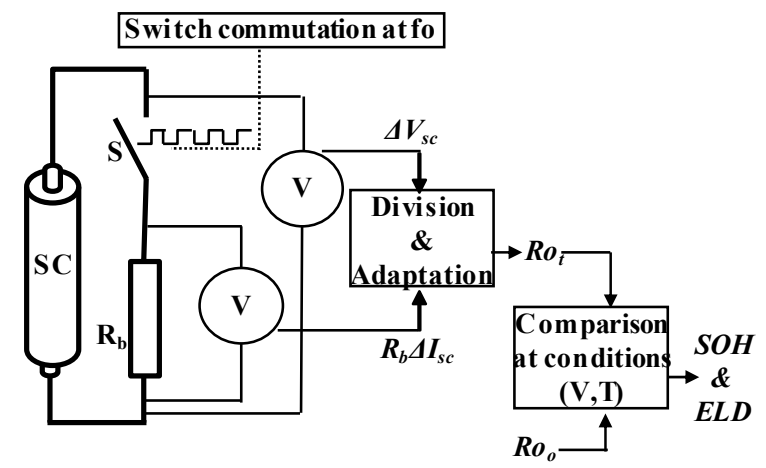

Fig. 5. New identification approach principle. SC: supercapacitor / S: switching MOSFET / $\mathrm{Rb}$ : balancing resistor / $\triangle \mathrm{Vsc}$ : ripple voltage at the terminals of the cell / $\Delta$ Isc: ripple current in the cell / Rot: actual Ro measured/ $\mathrm{Ro}_{0}$ : initial Ro measured. position.

\subsection{Health monitoring principle}

The health monitoring principle was inspired from the work presented in [31], which deals with the electrolytic capacitor diagnosis by the monitoring of its equivalent series resistance's evolution.

To estimate the state of health $(\mathrm{SOH})$ or the estimated life duration (ELD), the principle consists on comparing the estimated $\mathrm{Ro}_{\mathrm{t}}$ with the new approach with its initial value Ro.

The state of health expression is represented by (2). This aging indicator is equal to $100 \%$ when the element is new and falls to $0 \%$ when its $\mathrm{Ro}_{\mathrm{t}}$ reaches the end of life criterion fixed here as the double of initial $\mathrm{Ro}_{0}$ for the same conditions. This expression can differ with a less end of life criterion.

$$
\operatorname{SOH}(\%)=\left(\frac{2 \cdot R o_{0}-R o_{t}}{R o_{0}}\right) \cdot 100
$$

The estimated life duration, ELD, allows anticipating the future failure of the storage element and enable predictive maintenance to ensure availability of the whole storage system.

This ELD is computed using the same variables: actual Rot, initial Roo, precedent Rot- $\Delta t$, (Rot, Rot-st and Roo are also under same voltage and temperature conditions) and a predefined time between two Ro measures $\Delta \mathrm{t}$. The ESR predictive evolution is inspired from linear evolution of ESR at specific voltage temperature and current solicitation [21][32][33][34]. Considering a linear evolution of the 
ESR, the ELD is expressed by (3). Fig. 6 represents the ELD principle.

$$
E L D=\left(\frac{2 \cdot R o_{0}-R o_{t}}{R o_{t}-R o_{t-\Delta t}}\right) \cdot \Delta t
$$

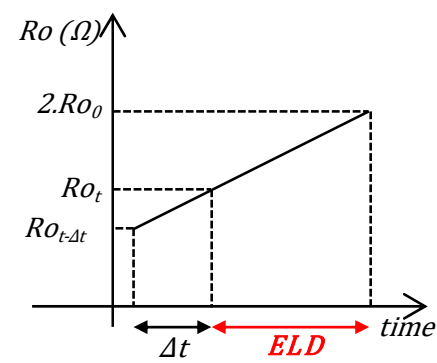

Fig. 6. ELD principle

The ELD and SOH computation requires comparison between actual $\mathrm{Ro}_{\mathrm{t}}$ and initial Ro. $\mathrm{R}_{0}$. Comparison should be made under same temperature and voltage conditions (see Fig. 5). However, those computations should be made at any cell voltage and temperature which still not the same in a long duration.

The ESR can depend on the cell temperature and/or voltage. Fig. 7 represents the $\mathrm{Rot}_{\mathrm{t}}$ variation for a $3000 \mathrm{~F} / 2.7 \mathrm{~V}$ supercapacitor according to its temperature.

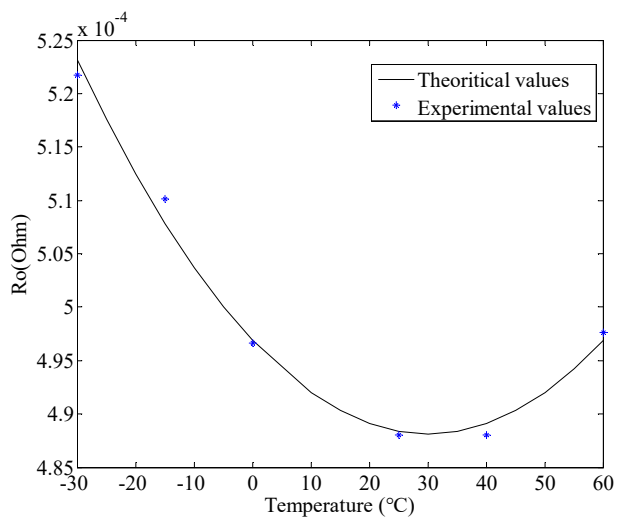

Fig. 7. $\mathrm{Ro}_{\mathrm{t}}$ versus cell temperature

$\mathrm{Rot}_{\mathrm{t}}(\mathrm{T})$ can be written as follows for this example:

$$
R o_{t}(T)=a \cdot T^{2}+b \cdot T+c
$$

Where,

$$
a=9.72 .10^{-9}\left(\Omega /{ }^{\circ} C^{2}\right) \quad b=-5.84 .10^{-7}\left(\Omega /{ }^{\circ} \mathrm{C}\right) \quad c=4.97 .10^{-4}(\Omega)
$$

Figure. 8 represents the Rot variation for a $3000 \mathrm{~F} / 2.7 \mathrm{~V}$ supercapacitor according to its terminal voltage.

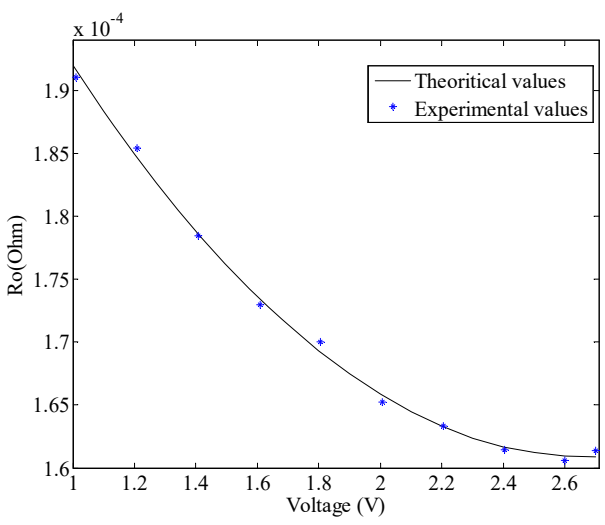

Fig. $8 . \mathrm{Ro}_{\mathrm{t}}$ versus cell terminal voltage

$\operatorname{Rot}(V)$ can be written as follows for this example:

$$
R o_{t}(V)=a \cdot V^{2}+b \cdot V+c
$$

Where,

$$
a=1.12 .10^{-5}\left(\Omega / V^{2}\right) \quad b=-5.98 \cdot 10^{-5}(\Omega / V) \quad c=2.41 .10^{-4}(\Omega)
$$

One can observe a little variation of ESR (less than $2 \%$ ) for positives temperatures which is coherent with literature $\lceil 29\rceil[35\rceil$. It could be explained by Rot origins. Indeed, Rot corresponds to the resistance of the electrolyte and to the conductive electrode material (active carbon and collector). Thus, at low temperatures, Rot increase is due electrolyte viscosity which become more important. Moreover, at high temperatures, Rot little increase is due to conductive electrode material (active carbon and collector).

Rot measured at $100 \mathrm{~Hz}$ increases at lowest voltages by $19 \%$ from a fully charged and discharged state (see Fig.8). This resistance can be assigned to the behaviour of the porous structure. Thus the low voltage alters the current flow of the porous structure and enhances cell resistance.

Frequently the range of temperature being limited, the variation of Rot versus temperature could be neglected.

Thus, to take into account temperature and voltage variation, the initial value Roo used to quantify the ELD and SOH is corrected to correspond to the Ro0 at actual environmental conditions. Using the cell voltage and temperature information already present in the SCM the correction is made thanks to the low expressed in (4) and/or (5).

This ESR dependency to voltage and temperature is supposed being identical for same supercapacitors at any state of aging. An initial characterization at different cell temperatures and voltages can be carried out in order to define a general relationship between cell's ESR and specific environmental conditions as in (4) and (5). For a module including several cells, it is also possible to use a thermal model if cell temperature measurements are not applied on each single cell [36][37][38].

In the following section, the implementation of this new method is described. Then, the balancing circuit test bench realization and the control carry out are detailed in order to estimate the actual Rot.

\subsection{Achievement}

The balancing circuit used is the controlled dissipative balancing circuit. This circuit is chosen because of its simple architecture, low cost and low maintenance. It is the most common structure on the market. This circuit placed at each cell's terminals includes a resistor and a switching MOSFET as shown in Fig. 5. 
Conventional balancing circuits equalize voltage between elements by dissipating the excess of energy for higher voltage cells through balancing resistors.

The new online identification method adds a new function to this balancing circuit. Rather than having a balancing control of Bang-Bang type, the switching MOSFET is controlled by a TTL wave with a frequency inside the resistive zone bandwidth. Thus, the cell response is resistive and the ratio between the supercapacitor's ripple voltage and its current provides the instantaneous Rot (see Fig. 5).

An experimental test bench is developed in order to validate this method. The test bench must ensure both conventional voltage equalization and Rot measurement.

The experimental test bench includes supercapacitors, balancing circuits and a human-machine interface. The storage system consists of a six chained supercapacitors. The balancing circuit is connected around each supercapacitor. Each balancing card includes two balancing circuits. The balancing circuit includes a $10 \Omega$ resistor, a switching MOSFET and some filters for adapting signal acquisition and extracting ripple signals required for characterization (see Fig. 9).

Balancing resistor was chosen as equal to $10 \Omega$. It corresponds to resistance value usually used for energy storage equalization. This resistor value allows $270 \mathrm{~mA}$ maximal current dissipation. In energy storage systems we aim to dissipate less than $1 \mathrm{~W}$ when balancing because of heat dissipation.

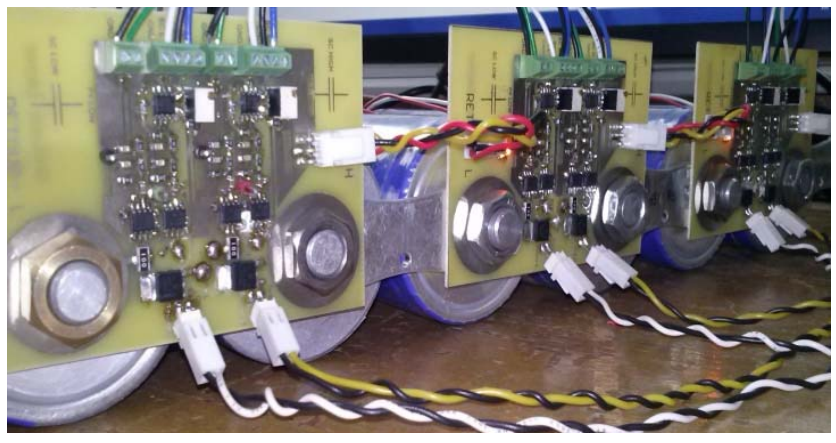

Fig. 9. Balancing cards realized

The balancing circuit is equipped with three voltage outputs (measured by SCM voltage sensors). The first voltage output, classical one, corresponds to the voltage at the terminal of the cell Vsc, required for equalization. Two supplementary outputs are added and correspond to voltage and current ripples required for Rot identification. The supplementary data are filtered before the acquisition by a band pass filter having a bandwidth corresponding to the resistive part $\Delta \mathrm{fr}$ in order to get the required cell ripple of current and voltage. Regarding the supercapacitor's current ripple measure, instead of adding a current sensor for each cell, the current is deduced from the voltage measured at the terminal of the balancing resistor $\mathrm{R}_{\mathrm{b}}$ (see Fig. 10).

As the ESR of the supercapacitor is low and the performance of the suggested method can be affected by the resistance of the connector, four measurement points were realized to solve this problem.

As the voltage ripple generated is very low (approximately 10 ${ }^{4} \mathrm{~V}$ ), an amplification should be added after the band pass filter to get a suitable voltage ripple for acquisition $(400 \mathrm{mV}$ in worst case with a $3000 \mathrm{~F}$ new supercapacitor). Figure 10 summarizes the above description.

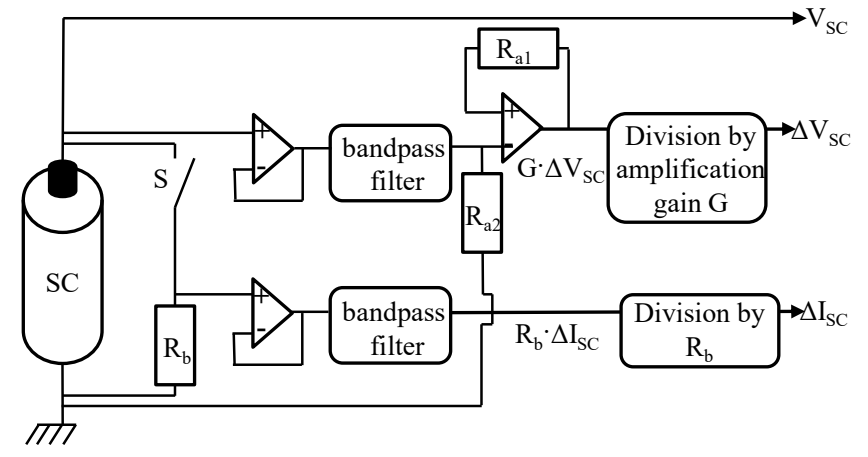

Fig. 10. Data measurement. S: switching mosfet / $\mathrm{R}_{\mathrm{b}}$ : balancing resistor / $\Delta \mathrm{V}_{\mathrm{Rb}}$ : voltages ripple at the terminal of the balancing resistor / $\mathrm{G} \Delta \mathrm{V}_{\mathrm{sc}}$ : voltage ripple at the terminal of the cell after amplification.

Figure 11 represents data acquired from the balancing circuit' supplementary outputs for a $3000 \mathrm{~F} / 2.7 \mathrm{~V}$ supercapacitor at rest at $25{ }^{\circ} \mathrm{C}$. In this example, the control of switching MOSFET is made by a TTL wave signal of $100 \mathrm{~Hz}$ frequency. $\Delta \mathrm{V}_{\mathrm{Rb}}$ represents the voltage ripple on the balancing resistor. $\mathrm{G} \Delta \mathrm{Vsc}$ represents the amplified voltage ripple at the terminal of the cell. Thus, by dividing peak-to-peak amplitude $\Delta \mathrm{V}_{\mathrm{Rb}}$ by the balancing resistor value $R_{b}$, it is possible to extract directly the cell current amplitude. Dividing peak-to-peak amplitude $\mathrm{G} \Delta \mathrm{V}_{\mathrm{sc}}$ by the amplification gain value $\mathrm{G}$ gives the cell voltage amplitude.

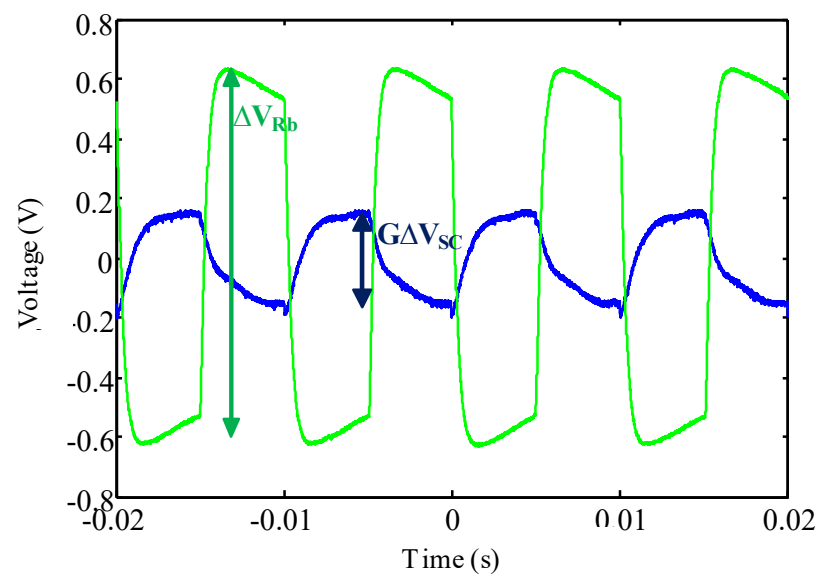

Fig. 11. Voltage ripples

The resulted Rot is then calculated according to the following equation (6):

$$
R o_{t}=\frac{\left(\frac{G \cdot \Delta V_{s c}}{G}\right)}{\left(\frac{\Delta V R_{b}}{R_{b}}\right)}
$$

For this example of application, the resulted ESR is equal to $2.47 \cdot 10^{-4} \Omega$.

The instrumentation and control panel is made using National Instrument (NI) equipment (PXI). It takes information of each cell and controls the switches for voltage balancing or ESR characterization and displays to the user a control panel with all the required information $\left(\mathrm{Ro}_{\mathrm{t}}\right.$, cell terminal voltage, switches states, supercapacitors current amplitude, supercapacitors voltage amplitude).

Figure 12 shows the complete test bench composed of six serial supercapacitors, six balancing circuits, the NI module for data acquisition, control and the human-machine interface panel. 


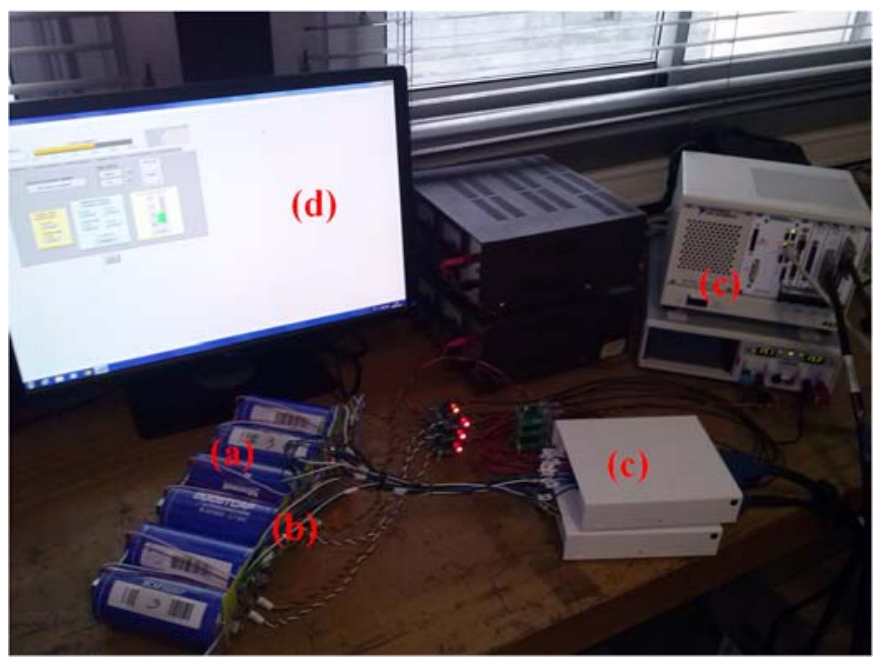

Fig. 12. Test bench realized with supercapacitors (a), balancing cards (b), NI data acquisition and control materials (c) and human-machine interface panel (d).

Even if in this case National Instrument equipment is used, the suggested method is simple and ripples required for Rot estimation could be measured with any classical management system equipment. Indeed, conventional management system instrumentation has an accuracy less than $10 \mathrm{mV}$ and voltage ripples made in worst case are bigger than $400 \mathrm{mV}$ thanks to amplifier.

However, if the voltage ripples are not enough wide for instrumentation used, they could be enlarged with bigger amplifier.

\section{Experimental results and application}

In this part of the paper, the exploitation of the experimental prototype is introduced in order to evaluate the new characterization method's results.

The theoretical analysis and experimental tests where made with electrochemical double layer capacitors (EDLC) from same manufacturer. Moreover, the physical principle and manufacture process being similar, the approach could be generalized to the whole EDLC brand.

Experimentation were made with different supercapacitors with different capacitances from $(650 \mathrm{~F}$ to $3000 \mathrm{~F})$ and with different state of health (new supercapacitors, used supercapacitors and aged supercapacitors). Tests were made with more than 15 different supercapacitors

Six supercapacitors of $3000 \mathrm{~F} / 2.7 \mathrm{~V}$ with different ages are chosen to present the test. First, storage system cells' characterization is realized individually with EIS for different voltage polarizations in order to extract the ESR at resonance frequency $\left(\mathrm{Ro}_{\mathrm{t}}\right)$. Second, the characterization is realized with the experimental test bench for the same supercapacitor voltages. The tables below show some results obtained at $25^{\circ} \mathrm{C}$.

Table I . New approach versus EIS characterization (New cell)
\begin{tabular}{|c|c|c|c|}
\hline \multirow{2}{*}{ Voltages (V) } & \multicolumn{3}{|c|}{ Supercapacitor "New cell" } \\
\cline { 2 - 4 } & $\boldsymbol{R o}_{\boldsymbol{t}}(\boldsymbol{m} \boldsymbol{\Omega})$ & $\boldsymbol{R o}_{\boldsymbol{t}}(\boldsymbol{m} \boldsymbol{\Omega})$ & \multirow{2}{*}{} \\
& $\boldsymbol{E} I \boldsymbol{S}$ & Balancing circuit & \\
\hline $1.1 \mathrm{~V}$ & 0.17 & 0.17 & 0.00 \\
\hline $2.1 \mathrm{~V}$ & 0.16 & 0.17 & 6.25 \\
\hline $2.7 \mathrm{~V}$ & 0.15 & 0.16 & 6.25 \\
\hline
\end{tabular}

Table II . New approach versus EIS characterization (Barely aged cell)

\begin{tabular}{|c|c|c|c|}
\hline \multirow{2}{*}{ Voltages (V) } & \multicolumn{3}{|c|}{ Supercapacitor "Barely aged cell" } \\
\cline { 2 - 4 } & $\boldsymbol{R o}_{\boldsymbol{t}}(\mathbf{m} \boldsymbol{\Omega})$ & $\boldsymbol{R o}_{\boldsymbol{t}}(\mathbf{m} \boldsymbol{\Omega})$ & $\Delta \boldsymbol{R o}_{\boldsymbol{t}}(\%)$ \\
& $\boldsymbol{E I S}$ & Balancing circuit & \\
\hline $1.1 \mathrm{~V}$ & 0.21 & 0.22 & 4.55 \\
\hline $2.1 \mathrm{~V}$ & 0.28 & 0.28 & 0.00 \\
\hline $2.7 \mathrm{~V}$ & 0.25 & 0.26 & 3.85 \\
\hline
\end{tabular}

Table III . New approach versus EIS characterization (Aged cell)

\begin{tabular}{|c|c|c|c|}
\hline \multirow{2}{*}{ Voltages (V) } & \multicolumn{3}{|c|}{ Supercapacitor “Aged cell” } \\
\cline { 2 - 4 } & $\boldsymbol{R o}_{\boldsymbol{t}}(\mathbf{m} \boldsymbol{\Omega})$ & $\boldsymbol{R o}_{\boldsymbol{t}}(\mathbf{m} \boldsymbol{\Omega})$ & \multirow{2}{*}{$\boldsymbol{R} \boldsymbol{R o}_{\boldsymbol{t}}(\%)$} \\
& $\boldsymbol{E} \boldsymbol{S} \boldsymbol{S}$ & Balancing circuit $^{*}$ & \\
\hline $1.1 \mathrm{~V}$ & 0.29 & 0.30 & 3.33 \\
\hline $2.1 \mathrm{~V}$ & 0.20 & 0.20 & 0.00 \\
\hline $2.7 \mathrm{~V}$ & 0.18 & 0.19 & 5.26 \\
\hline
\end{tabular}

Thus we can consider that this estimation method is reliable and that its results represent the actual ESR of the monitored cell. Indeed, differences between the laboratory method and the online new approach do not exceed $7 \%$.

A statistical study was made in order to analyses the repeatability of the measurement. Repeating the ESR measure 90 times with same condition for a $3000 \mathrm{~F}$ supercapacitor at $2.2 \mathrm{~V}$ and $39^{\circ} \mathrm{C}$, the final measurement uncertainty of ESR is $\mp 0.35 \mu \Omega$. Repeatability test was made at $39^{\circ} \mathrm{C}$ and $2.2 \mathrm{~V}$ to be in worst case with low ESR (see fig. 7 and 8). This final uncertainty of measurement is computed for a confidence level of $95 \%$. The uncertainty of ESR resulted from this study corresponds to $0.12 \%$ as Ro accuracy.

The experimental results presented are based on the $3000 \mathrm{~F}$, $2.7 \mathrm{~V}$ supercapacitors because it is also the most critical case. In fact, supercapacitors with lower capacitances have higher ESR which is simpler to be measured.

The results of the proposed new approach are compared with the results of electrochemical impedance spectroscopy (EIS) which is a famous characterization method in energy storage area [39].

Thus, values collected demonstrate clearly the accuracy and the good performance of the new online identification method. After the study of the accuracy of the new characterization approach, the final step is to estimate the state of health $(\mathrm{SOH})$ of the monitored element and the estimated life duration (ELD) corresponding to the time between the measurement and the predictive end of life of the system. The ELD and SOH computation are based on linear evolution of ESR for specific voltage and temperature. However, even if evolution of supercapacitor ESR differs from linear one, it doesn't disturb the health monitoring. First, the ESR evolution is very slow over aging. Second, the new approach of balancing control allows continuous supervision of this parameter. Thus, the ELD and the SOH are always actualized by the actual cell ESR, so they still close to the real evolution which could be not linear.

\section{Conclusion}

For safety and maintainability reasons, it is compulsory to follow the supercapacitor's state of health evolution in order to predict the replacement of the potential defective elements and to 
extend the lifespan of the storage system. Defining precisely the storage element state requires using specific equipment such as an impedance spectrometer. This means that each element should be characterized individually and must be extracted of its environment. Many storage system applications (automotive, uninterruptible power supply...) do not allow cell characterization off-line. In this case, a powerful algorithm is used to estimate the state of health of the cell. It uses cell's measured data (voltage, current and temperature) during it is charging or discharging with complex algorithms and different approximations. The more the estimation is precise, the more the algorithm is complex. The work presented in this paper has several advantages. First, obtained results are accurate with minimum hardware and software needs. Second, it uses equipment already present in the storage system applications. There is no need to extract the cell from its environment and to use powerful software and complex algorithms. In fact, classical mathematical operations and some added components are able to find the real age of the monitored cell. Moreover, the balancing circuit conventional function equalizes the voltage between elements perfectly. This realization can be implemented in a real supercapacitor management system.

Finally, the suggested new method is very simple, economical and guarantees accurate $\mathrm{SOH}$ and lifespan determination of electrical energy storage system.

\section{References}

11] S. Kumagai, K. Mukaiyachi, and D. Tashima, "Rate and cycle performances of supercapacitors with different electrode thickness using non-aqueous electrolyte," J. Energy Storage, vol. 3, pp. 10-17, Oct. 2015.

[2] S. V. Rajani, V. J. Pandya, and V. A. Shah, "Experimental validation of the ultracapacitor parameters using the method of averaging for photovoltaic applications," J. Energy Storage.

[3] W. Sarwar, M. Marinescu, N. Green, N. Taylor, and G. Offer, "Electrochemical double layer capacitor electro-thermal modelling," J. Energy Storage, vol. 5, pp. 10-24, Feb. 2016.

[4] D. Torregrossa, K. E. Toghill, V. Amstutz, H. H. Girault, and M. Paolone, "Macroscopic indicators of fault diagnosis and ageing in electrochemical double layer capacitors," J. Energy Storage, vol. 2, pp. 8-24, Aug. 2015 .

[5] P. Sharma and T. S. Bhatti, "A review on electrochemical doublelayer capacitors," Energy Convers. Manag., vol. 51, no. 12, pp. 2901 $-2912,2010$

[6] P. Bubna, S. G. Advani, and A. K. Prasad, "Integration of batteries with ultracapacitors for a fuel cell hybrid transit bus," J. Power Sources, vol. 199, pp. 360-366, Feb. 2012.

[7] A. Burke and M. Miller, "The power capability of ultracapacitors and lithium batteries for electric and hybrid vehicle applications," $J$. Power Sources, vol. 196, no. 1, pp. 514-522, Jan. 2011.

[8] F. A. Inthamoussou, J. Pegueroles-Queralt, and F. D. Bianchi, "Control of a Supercapacitor Energy Storage System for Microgrid Applications," Energy Convers. IEEE Trans. On, vol. 28, no. 3, pp. 690-697, Sep. 2013.

[9] A. David, Battery Management Systems for large Lithium-Ion Battery Pack. Boston, London: Artech House, 2010.

[10] A. Affanni, A. Bellini, G. Franceschini, P. Guglielmi, and C. Tassoni, "Battery choice and management for new-generation electric vehicles," Ind. Electron. IEEE Trans. On, vol. 52, no. 5, pp. 1343 1349, Oct. 2005.

[11] Y. Diab, P. Venet, and G. Rojat, "Comparison of the Different Circuits Used for Balancing the Voltage of Supercapacitors: Studying Performance and Lifetime of Supercapacitors," in ESSCAP, 2006.

[12] Yanqing Qu, Jianguo Zhu, Jiefeng Hu, and B. Holliday, "Overview of supercapacitor cell voltage balancing methods for an electric vehicle," in ECCE Asia Downunder (ECCE Asia), 2013 IEEE, 2013, pp. 810814.

[13] Jian Qi and D. D.-C. Lu, "Review of battery cell balancing techniques," in Power Engineering Conference (AUPEC), 2014 Australasian Universities, 2014, pp. 1-6.

[14] F. Ibanez, J. Vadillo, J. M. Echeverria, and L. Fontan, "Design methodology of a balancing network for supercapacitors," in Innovative Smart Grid Technologies Europe (ISGT EUROPE), 2013 4th IEEE/PES, 2013, pp. 1-5.
[15] H. K. P. Khant, K. Yamakita, K. Matsui, and M. Hasegawa, "Various voltage equalizers for EDLCs using CW circuit," in Industrial Electronics (ISIE), 2013 IEEE International Symposium on, 2013, pp. $1-6$.

[16] T. H. Phung, A. Collet, and J.-C. Crebier, "An Optimized Topology for Next-to-Next Balancing of Series-Connected Lithium-ion Cells," Power Electron. IEEE Trans. On, vol. 29, no. 9, pp. 4603-4613, Sep. 2014

[17] M.-Y. Kim, J.-H. Kim, and G.-W. Moon, "Center-Cell Concentration Structure of a Cell-to-Cell Balancing Circuit With a Reduced Number of Switches," Power Electron. IEEE Trans. On, vol. 29, no. 10, pp. 5285-5297, Oct. 2014.

[18] H. Rahimi-Eichi, F. Baronti, and M.-Y. Chow, "Online Adaptive Parameter Identification and State-of-Charge Coestimation for Lithium-Polymer Battery Cells," Ind. Electron. IEEE Trans. On, vol. 61, no. 4, pp. 2053-2061, Apr. 2014.

[19] F. Zhang, G. Liu, L. Fang, and H. Wang, "Estimation of Battery State of Charge With Observer: Applied to a Robot for Inspecting Power Transmission Lines," Ind. Electron. IEEE Trans. On, vol. 59, no. 2, pp. 1086-1095, Feb. 2012.

[20] R. German, A. Sari, P. Venet, Y. Zitouni, O. Briat, and J.-M. Vinassa, "Ageing law for supercapacitors floating ageing," in Industrial Electronics (ISIE), 2014 IEEE 23rd International Symposium on, 2014, pp. 1773-1777.

[21] P. Azais, L. Duclaux, P. Florian, and D. Massiot, "Causes of supercapacitors ageing in organic electrolyte," J. Power Sources, vol 171, pp. 1046-1053, 2007.

[22] R. German, A. Sari, P. Venet, O. Briat, and J.-M. Vinassa, "Study of static converters related ripple currents effects on supercapacitors ageing within DC networks," in Industrial Electronics (ISIE), 2015 IEEE 24th International Symposium on, 2015, pp. 1302-1307.

[23] R. German, A. Hammar, R. Lallemand, A. Sari, and P. Venet, "Novel Experimental Identification Method for a Supercapacitor Multipore Model in Order to Monitor the State of Health," Power Electron. IEEE Trans. On, vol. 31, no. 1, pp. 548-559, Jan. 2016.

[24] R. Kotz, P. W. Ruch, and D. Cericola, "Aging and failure mode of electrochemical double layer capacitors during accelerated constant load tests," J. Power Sources, vol. 195, no. 3, pp. 923 - 928, 2010.

[25] A. Hammar, P. Venet, R. Lallemand, G. Coquery, and G. Rojat, "Study of Accelerated Aging of Supercapacitors for Transport Applications," Ind. Electron. IEEE Trans. On, vol. 57, no. 12, pp. $3972-3979$, Dec. 2010

[26] R. Chaari, O. Briat, J. Y. Deletage, E. Woirgard, and J.-M. Vinassa, "How supercapacitors reach end of life criteria during calendar life and power cycling tests," Microelectron. Reliab., vol. 51, no. 911, pp. 1976 - 1979, 2011.

[27] R. German, P. Venet, A. Sari, O. Briat, and J. M. Vinassa, "Comparison of EDLC impedance models used for ageing monitoring," in Renewable Energies and Vehicular Technology (REVET), 2012 First International Conference on, 2012, pp. 224 229.

[28] H. Gualous, H. Louahlia, and R. Gallay, "Supercapacitor Characterization and Thermal Modelling With Reversible and Irreversible Heat Effect," Power Electron. IEEE Trans. On, vol. 26, no. 11, pp. 3402-3409, 2011.

[29] G. Piłatowicz, A. Marongiu, J. Drillkens, P. Sinhuber, and D. U. Sauer, "A critical overview of definitions and determination techniques of the internal resistance using lithium-ion, lead-acid, nickel metal-hydride batteries and electrochemical double-layer capacitors as examples," J. Power Sources, vol. 296, pp. 365-376, Nov. 2015.

[30] W. Lajnef, J.-M. Vinassa, O. Briat, S. Azzopardi, and E. Woirgard, "Characterization methods and modelling of ultracapacitors for use as peak power sources," J. Power Sources, vol. 168, no. 2, pp. 553 560, 2007.

[31] P. Venet, F. Perisse, M. H. El-Husseini, and G. Rojat, "Realization of a smart electrolytic capacitor circuit," Ind. Appl. Mag. IEEE, vol. 8, no. 1, pp. 16-20, Feb. 2002

[32] P. Kreczanik, P. Venet, A. Hijazi, and G. Clerc, "Study of Supercapacitor Aging and Lifetime Estimation According to Voltage, Temperature, and RMS Current," Ind. Electron. IEEE Trans. On, vol. 61, no. 9, pp. 4895-4902, Sep. 2014.

[33] R. German, A. Sari, P. Venet, O. Briat, and J.-M. Vinassa, "Study on specific effects of high frequency ripple currents and temperature on supercapacitors ageing," Proc. 26th Eur. Symp. Reliab. Electron Devices Fail. Phys. Anal. ESREF 2015, vol. 55, no. 9-10, pp. 20272031, Aug. 2015.

[34] M. Ayadi, O. Briat, R. Lallemand, A. Eddahech, R. German, G. Coquery, and J. . Vinassa, "Description of supercapacitor 
performance degradation rate during thermal cycling under constant voltage ageing test," SI ESREF 2014, vol. 54, no. 9-10, pp. 1944 1948, Sep. 2014

[35] R. Kotz, M. Hahn, and R. Gallay, "Temperature behavior and impedance fundamentals of supercapacitors," J. Power Sources, vol. 154 , no. 2 , pp. $550-555,2006$

[36] D. Torregrossa and M. Paolone, "Modelling of current and temperature effects on supercapacitors ageing. Part II: State-of-Health assessment," J. Energy Storage.

[37] D. Torregrossa and M. Paolone, "Modelling of current and temperature effects on supercapacitors ageing. Part I: Review of driving phenomenology," J. Energy Storage.

[38] A. Hijazi, P. Kreczanik, E. Bideaux, P. Venet, G. Clerc, and M. Di Loreto, "Thermal Network Model of Supercapacitors Stack," Ind. Electron. IEEE Trans. On, vol. 59, no. 2, pp. 979-987, Feb. 2012.

[39] H. Blanke, O. Bohlen, S. Buller, R. W. De Doncker, B. Fricke, A. Hammouche, D. Linzen, M. Thele, and D. U. Sauer, "Impedance measurements on lead-acid batteries for state-of-charge, state-ofhealth and cranking capability prognosis in electric and hybrid electric vehicles," Sel. Pap. Ninth Eur. Lead Battery Conf. Eur. Lead Battery Conf., vol. 144, no. 2, pp. 418-425, Jun. 2005. 